\title{
Correction to: Characterization of a hybrid zone between two annual killifish genus Austrolebias from the Biosphere Reserve and Ramsar Sites in South America
}

\author{
Graciela García (D) - Verónica Gutiérrez • Néstor Ríos • Nicolás Papa • \\ Sebastián Serra $\cdot$ Marcelo Loureiro
}

Published online: 9 September 2020

(C) Springer Nature Switzerland AG 2020

Correction to: Hydrobiologia (2020) 847:421-442 https://doi.org/10.1007/s10750-01904104-0

Due to an unfortunate turn of events, the incorrect caption of Fig. 2 appeared in the original publication.
Figure 2 and its correct caption is published here and should be treated as definitive.

The original article can be found online at https:// doi.org/10.1007/s10750-019-04104-0.

G. García $(\bowtie) \cdot$ V. Gutiérrez · N. Ríos · S. Serra Sección Genética Evolutiva, Facultad de Ciencias, UdelaR, Iguá 4225, CP. 11400 Montevideo, Uruguay e-mail: ggarcia@fcien.edu.uy

N. Papa

Sección Biología Celular, Facultad de Ciencias, UdelaR, Iguá, 4225, 11400 Montevideo, Uruguay

S. Serra $\cdot$ M. Loureiro Departamento de Ecología Y Evolución, Facultad de Ciencias, UdelaR, Iguá 4225, 11400 Montevideo, Uruguay

S. Serra $\cdot$ M. Loureiro

Sección Ictiología, Museo Nacional de Historia Natural, Montevideo, Uruguay 
Fig. 2 Morphotypes and pigmentation patterns of individuals belonging to two parental species $A$. charrua and $A$. reicherti and their putative hybrid populations. Males of A. charrua (A-D) from putative hybrid populations (E-H), and males of $A$. reicherti $(\mathbf{I}, \mathbf{J})$. Females of A. charrua (K), the putative hybrid populations (L), and from $A$. reicherti $(\mathbf{M})$

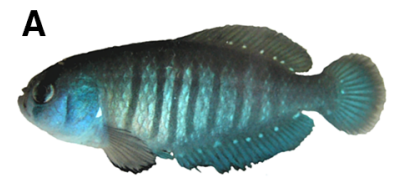

B
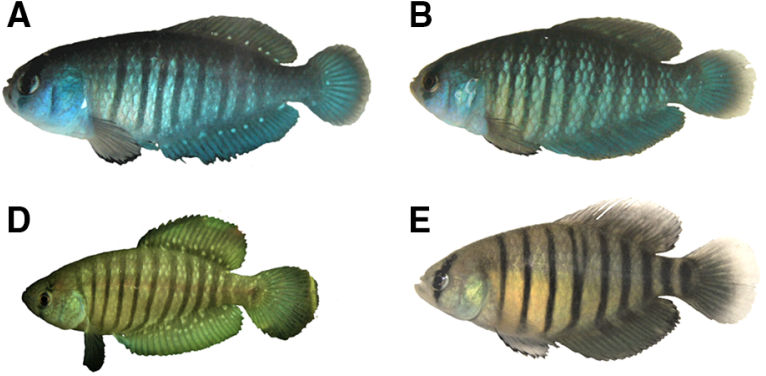

G

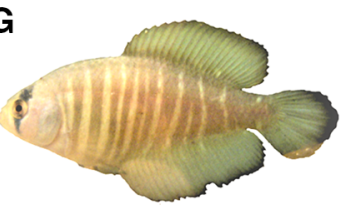

J

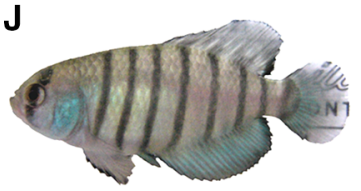

M

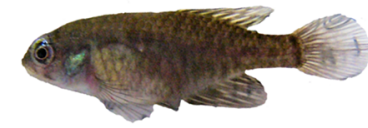

E

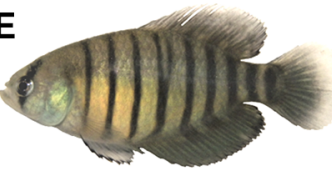

H

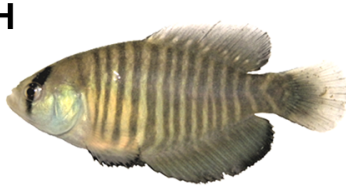

K

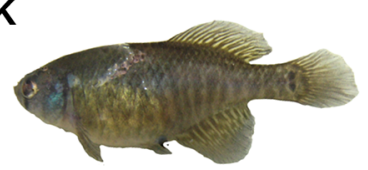

C

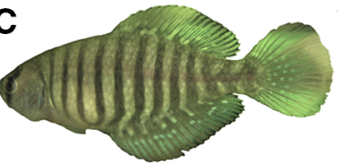

$\mathbf{F}$
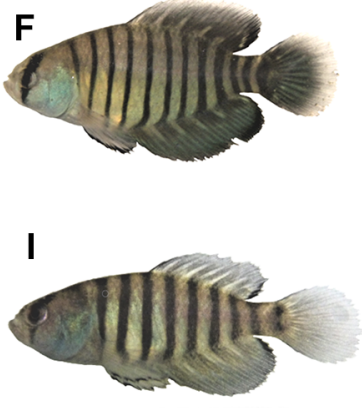

$\mathbf{L}$

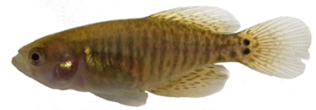

Publisher's Note Springer Nature remains neutral with regard to jurisdictional claims in published maps and institutional affiliations. 